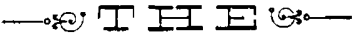 Journal of the American Medical Association. EDIFED FOE TIIE ASSOCIATIOIV DY IT. S. DATIS.
}

PUBLISHED WEEKIY.
VoL. I.
Saturday, September i 5, i 883 .
No. го.

\section{ORIGINAL ARTICLES.}

\section{ON EARLY TAPPING IN CASES OF ASCITES,}

\author{
BY AUSTIN FLINT, M.D.
}

Read at the meeting the of Section on Medicine of the British Medical Association, in Liverpool, August 2, 1883.]

Mr. President and Gentlemen: The subject which I have selected for a short paper cannot, perhaps, be said to belong in the higher regions of pathology and practice, but it is one which, as it seems to me, has considerable material importance.

Most writers on practical medicine at the present time, as in the past, recommend tapping, in cases of ascites, as a last resort, to be employed only when the dropsical accumulation has occasioned an alarming interference with respiration, and after other measures of treatment have proved ineffectual. ${ }^{1}$ The practice of most physicians now, as hitherto, I suppose to be in accordance with this recommendation. Many years ago I was led by reasoning and by clinical observation to advocate tapping early in cases of that affection. In 1863 I communicated for the American Journal of Mcdical Sciences an article entitled "Clinical Report on Hydro-peritonæum Based on an Analysis of Forty-six Cases." The histories of these forty-six cases I had recorded. The results of the analysis seemed to show the utility of tapping early and as often as the dropsy returned. Since the date of that report, in the cases which have come under my observation in hospital and in private practice, I have pursued this course of treatment, and the results have appeared to confirm its utility.

The objections brought against tapping early, and it may be, repeatedly, in cases of ascites, are-

rst. It is liable to be followed by alarming prostration, and it may even prove fatal in subjects greatly enfeebled.

2d. It sometimes proves fatal by inducing peritonitis.

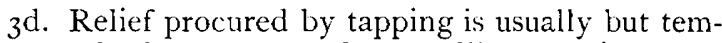
porary, the dropsy, as a rule, speedily returning.

4 th. With every return of the dropsy a lage quantity of albumen is withdrawn from the blood. The vital forces are thereby impaired, and, although temporary relief may be obtained, the duration of life is shortened.

In no instance under my observation has either a fatal result or alarming prostration followed tapping.

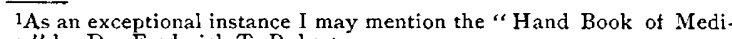
cine," by Dr. Frederick T. Roberts.
}

On the contrary, relief, immediate and pronounced, has been invariable. I have met with but a single instance in which peritonitis was induced by tapping. In that instance, ascites from cirrhosis was associated with general dropsy from chronic Bright's disease, the latter, as is well known, involving a predisposition to inflammation of serous structures.

All danger in the direction of either exhaustion or peritoneal inflammation is probably avoided if, instead of the ordinary mode of tapping, aspiration be employed. The slowness with which the liquid is withdrawn by aspiration, obviates any risk of exhaustion, and the insignificant puncture with a small trochar can hardly give rise, in any case, to peritonitis.

Two objections may be raised to aspiration. One of these is the length of time required for the operation, and the fatigue on the part of the operator, in removing by this method a large quantity of liquid. It is an answer to this objection that the manual part of aspiration does not call for a skilled hand, and therefore, the assistance of a nurse or an attendant may be made available. The other objection is the inconvenience often of having at hand an aspirator. This objection is met by substituting for the beautiful but cumbersome apparatus of Dieulafoy, or the adaptation of the stomach pump by Braditel, a very simple arrangement which I devised many years ago for thoracentesis. The instrument used is that known in the United States as Davidson's syringe. ${ }^{1}$ It consists of an India rubber hollow ball of a size to be readily grasped by the hand, connected with which are two India rubber tubes. By the introduction within the base of moveable valves, one of the tubes is made afferent, and the other efferent. At the end of the afferent tube is an attachment for connecting with it a small counter. The aspiration through this tube is effected by the expansion of the central ball, and the latter by compression with the hand, is emptied through the efferent tube. For thoracentesis and all other applications of aspiration, this homely instrument is all that could be desired, except in an æsthetic point of view. Its advantages are its cheapness, its portability, its durability, and its being always in urder for immediate use.

The more important of the objections which have been stated to tapping early and repeatedly in cases of ascites, are that the relief which it may afford is but temporary, and that life is shortened by the impairment of the vital forces consequent on the loss of the nutritive constituents of the blood.

Regarding these objections from a rational stand-

\footnotetext{
${ }^{1} \mathrm{My}$ instrument is called in England Higginson's Syringe.
} 
point, the measures of treatment pursued by those who delay as long as possible tapping, are to be contrasted with the advantages of the latter. The measures other than tapping generally have for their object the removal or the diminution of the dropsy. The measures are sudorifics, diuretics, and hydrogogue cathartics. Sudorifics accomplish so little, that nothing is to be said in their favor. Very little can be said in favor of diuretics. The instances are rare in which much is accomplished by this class of remedies. Hydrogogue cathartics are more efficient. Elaterium, the pulvis purgans and the saline carthartics sometimes diminish considerably, and they may even remove the dropsy. Their uncertainty, however, must be admitted, and, when more or less effective, the object is usually accomplished slowly, not a little depression and perturbation being caused by their repetitions. Now, is it not a rational conclusion, inasmuch as by tapping the removal of the dropsy is effected with certainty within a few hours, or even minutes, the operation being harmless and giving very little pain, that this method of treatment is to be preferred? And in view of these advantages of tapping, why waste time in an endeavor to effect the object by drugs?

Here, as in regard to all therapeutical questions, an appeal must be taken from reason to experience. And in deductions from experience, as well as in rational conclusions, the different affections of which ascites is a symptom are to be taken into account. If the ascites be symptomatic of malignant disease, and where it depends on persistent occlusion of the portal vein from thrombosis, embolism, or the pressure of a tumor, tapping, as well as other measures for the removal of the dropsy, cannot be expected to promise often more than temporary relief. But in the cases falling in this category, it has seemed to me evident that life is prolonged by tapping, repeated as often as need be ; and, on the other hand, life has seemed to me to have been shortened by the use of depressing and perturbating drugs. In the great majority of cases, as is well known, cirrhosis of the liver is the affection having a causative relation to the dropsy. Now, in a certain proportion of these cases, the dropsy is dependent on auxiliary causes cooperating with the hepatic lesion. Anæmia, anorexia, impaired digestion, etc., the effects of alcoholism or of other agencies, are more or less involved in the causation of ascites. Without these auxiliary causes, dropsy would not have occurred, and the cirrhosis perhaps would have been well tolerated. 'These coöperating causes are often, to a greater or less extent, removable. The discontinuance of spirit-drinking may sometimes suffice for their removal. These statements are based on the study of cases which I have recorded. Let the tapping be resorted to as soon as the dropsy occasions notable inconvenience ; let auxiliary causes be removed as far and as soon as practicable ; let the patient be placed on a tonic and analeptic treatment; let depressing and perturbating drugs be avoided; let tapping be promptly repeated if the dropsy return, and, notwithstanding the existence of a certain amount of cirrhosis, there may be a restoration to fair general health, and its continuance for an indefinite period.
My collection of recorded cases furnisines illustrations of the correctness of this operation. It may be that the dropsy will not return after a single tapping. More frequently, the tapping has to be repeated. The intervals between the repetitions, in different cases, and at different periods in the same case, differ greatly. Even if tapping be repeated many times and after short intervals, I believe the rule to tap as early and as often as the dropsy occasions inconvenience, to be better than to let the dropsy remain, or to undertake to lessen it by hydrogogue cathartics. In one of my recorded cases, the patient was tapped 30 times within 18 months. $\mathrm{He}$ had come to regard this measure as a trivial affair, and on one occasion, medical aid not being at hand, he tapped himself, using the blade of a pair of scissors instead of a trocar, and introducing a common clay pipe stem as a canula! He was accustomed, the day after a tapping, to go about his business as usual. This was a dispensary case, and was lost sight of after the thirtieth tapping. At that time he was anæmic, but able to take pretty active exercise. There are some cases of ascites in which a causative lesion, if one exist, may remain permanently innocuous, at least when not associated with auxiliary causes, as shown by the recovery and the continuance of perfect health. Of my recorded cases, a few are in this category.

In concluding my clinical report on ascites, published twenty years ago, I used the following language: "Unpromising as are the majority of the cases of ascites, I cannot but believe that, as regards prolongation of life and as much improvement as is compatible with existing structural disease, the success of medical practice would be enhanced by employing less than has been the custom of physicians, diuretics, hydrogogue cathartics, and other depressing remedies, by resorting earlier than is usually done to tapping, and by a greater reliance on tonic medication, together with hygienic measures to invigorate and strengthen the system.'

In conclusion now, after the added experience of twenty years, I hold to the same belief, with a stronger conviction of its correctness, as based on reason and clinical facts.

SUPPLEMENT TO THE PAPER ON EARLY TAPPING IN CASES OF ASCITES, PY AUSTIN FliNT, M.D.

As a supplement to the paper on Early Tapping in Cases of Ascites, condensed abstracts of the histories of twelve cases are appended. The sole object in submitting these cases is to illustrate the practical points presented in the paper. All details not bearing upon these practical points are omitted. The cases are appended without comments, leaving the reader to take note of the particular bearings of the facts, which are cited from the histories for the object just stated.

Case I.-Repeated tappings after short interzals. The patient, at the time of the first tapping, greatly prostrated. Progressive improvement.

A woman, aged 36 , who had been employed in a liquor shop, was admitted into hospital August I3. She was confined to the bed and greatly prostrated. She was jaundiced. The abdomen was very tense. 
A pailful of liquid was removed by tapping. Ten days after the tapping her condition was much improved. At that time the following note was written : "When this patient came under observation she was extremely prostrated. I felt sure that active hydrogogues would have been dangerous, and I felt equally sure that she would have succumbed under the disturbance caused by the greatly distended abdomen. I am persuaded that the continuance of life, in this case, was due to the tapping."

September 3 the dropsy had returned, and the patient was again tapped. September i 6 she was again tapped, and again on October 30 . Shortly after the last tapping she left the hospital. She progressively improved, notwithstanding the repeated tappings after short intervals. There were no cardiac nor renal complications in this case. The spleen was much enlarged.

Case II.-Tapping once, and no return of the dropsy, the patient apparently well two months after the tapping.

A woman, aged 35 , was admitted into hospital in January. Enlargement of the abdomen had existed for two months. The enlargement, at the time of admission, was very great, and attended with much suffering. The patient was confined to her bed. Tapping at once was resorted to, and a bucketful of liquid removed. Notable immediate relief followed. Improvement was noticed. A month after the tapping, the patient was attacked with cholera morbus. There was no return of the dropsy. After recovery from the cholera, she left the hospital reporting quite well.

Case III.-Tapping after ineffectual treatment by hydrogogues Three months after the tapping the dropsy had not returned.

A man aged 50, a spirit drinker, was admitted into hospital in September. Enlargement of the abdomen began three weeks before his admission. elaterium was given repeatedly, causing only a temporary diminution of the dropsy.

He was tapped in December. The abdomen was then much distended, and the lower limbs swelled. There was considerable emaciation. March 30 , it was noted that there had been no return of the dropsy; that the patient reported quite well, and that he had a healthy aspect.

Case IV.-Ascites followed by phthisis, No return of dropsy after 3 years. Notable cnlargement of abdominal veins.

A man, aged 46 , had had ascites 3 years before his admission into hospital. The dropsy disappeared in 7 weeks. Treatment not noted. He quit spirit drinking in a great measure afterward. There had been no return of the dropsy. He had had good health, and had been able to do full work as a ship carpenter for several months, when the symptoms of pulmonary disease began. On his admission he had pulmonary phthisis and chronic laryngitis. He noticed enlargement of the abdominal veins first at the time of the disappearance of the dropsy. On his admission, the appearance of the abdomen was described as follows: "The abdomen presents a very remark- able spectacle. The abdominal veins are greatly dilated and varicose. This appearance is most marked on each lateral part of the interior aspect of the abdomen, the veins extending upward nearly to the level of the nipples, without the mammary line. An enlarged vein extends along the median line, and one on each side of this line. The blood flows in all these veins from below upward.

Case $V .-$ No return of ascites after a single tapping for a period of two years..

A seaman, aged $\mathbf{2 2}$, a spirit drinker formerly, was admitted into hospital with typhoid fever, from which he recovered. Two years before his admission he had ascites, and was tapped. He quit the use of spirits, and there had been no return of the dropsy. There was great enlargement of the superficial veins of the abdomen in this case.

Case VI.-Cirrlosis of the liver in a notable degree without ascites.

A woman, aged 33, when admitted into hospital was feeble and anæmic. She had had several attacks of hæmatemesis. She was progressively improving, when 4 months after her admission, she was seized with pneumonia, which proved fatal. There had been no ascites. The autopsy showed in addition to the pneumonia, a hobnail-liver, weighing only two pounds; also disease of kidneys. This case is introduced as illustrative of the tolerance of cirrhosis as regards dropsy.

Case VII.-Ascites in a case in which tapping was twice performed, and no return of the dropsy a month after the last tapping.

A woman, aged 40; a spirit drinker, was admitted into hospital, with ascites, in October. She was at once tapped with immediate relief. Early in December, she was again tapped. A month afterward there had been no return of the dropsy. The patient was then discharged, reporting and looking well.

Case VIII.-Ascites treated ineffectually with elaterium. Tapping tzice, and no return of the dropsy cwo months after the second tapping.

A woman, aged 25 , applied at a college dispensary, in April, with ascites which had existed for four months. Some diminution of the dropsy was effected by elaterium, but the diminution was temporary. She was then tapped, and, after two months, the tapping was repeated. Two months afterward there had been no return of the dropsy, and she reported quite well.

Case IX.-Ascites treated by tapping, and return of the dropsy repeatedly after long intervals.

A man, the age not stated, a spirit drinker, was admitted into hospital with ascites, which had existed for two months. It was developed after intermittent fever. He gave the following history: Eight years prior to his admission he had ascites, and after four months was tapped. The tapping was repeated after two weeks. There was no return of the dropsy, and he had good health for six years. The dropsy then returned, and he had also hæmatemesis. Five weeks afterward he was tapped. The dropsy returned but disappeared under the use of medicines, and he remained free from it for about two years. He had 
continued to drink spirits more or less treely. The subsequent history is not noted.

Case X.-Ascites referable to thrombosis of portal acin. Tapping ten times within three months. No return of the dropsy, and the patient in fair health elezen y'ears afterward. Diet of milk and gingerbread.

This patient, a man 45 years of age, of good habits, came under my observation, in private practice, eleven years ago. He had been ill for several weeks, his symptoms having been supposed to denote thrombosis of the portal vein. I may mention that the patient's wife, a very intelligent woman, had endeavored to study her husband's case by reading medical books, and the reason of my being called in consultation was the advocacy of tapping in my notes on the Practice of Medicine. The abdomen was greatly distended. Owing to the feebleness of the patient, it had been deemed hazardous to resort to tapping. This measure, however, at my suggestion, was at once employed, and notable, immediate relief followed. Within three months the patient was tapped ten times, The aggregate amount of licuid removed was about 350 pounds. After the last tapping there was only a moderate accumulation of liquid, and this gradually disappeared. The patient slowly recovered, and for the past ten years he has had fair health. His aspect is healthy, and he is accustomed to walk from four to six miles daily.

During the period when the tappings were repeated, and for more than a year afterward, this patient confined his diet strictly to milk and gingerbread. These articles have constituted the greater part of his diet ever since. He has taken neither fish nor fowl nor meat of any kind. $\mathrm{He}$ is accustomed to take, in addition to the milk and gingerbread, rice, oysters, eggs and asparagus. On one occasion he was led to indulge for several days in the luxury of eating boiled green Indian corn. This was followed by a moderate return of the ascites, which disappeared under the use of diuretics. After this experience he resolved to stick to the diet to which he had become habituated.

Case XI. - Case of supposed portal thrombosis. Tapping repeated tentimes. Complete recovery.

This patient, a man aged 47 , came under my observation in private practice, in March, 1880 . His ilness began in December, 1880 . He was then in Kansas. He was there considered to have malarial fever and inflammation of the liver and spleen. Between December 8 and 27 he had three attacks of næmatemesis and became greatly prostrated. Following this, ascites developed, and cedema of the lower limbs. On February 3, I881, he was. tapped for the first time, and twenty quarts of liquid removed. He was again tapped February $\mathbf{I}$, and March 2. He was then brought to Hoboken, N. J., and was seen by me, in consultation with Dr. T. R. Varick, of Jersey City. He was tapped by Dr. Varick March 20, April 3, April 14, April 25, May 9, June 6 and July io. When seen by me before the tappings by Dr. Varick, he was greatly emaciated and prostrated. He was, however, able to take food freely, and notwithstanding the tappings, he pro- gressively improved. A relative informs me by letter, dated May 3I, I883, that he is in better health than for many years before his illness. In addition to the tappings, the treatment by Dr. Varick was tonic and analeptic. He also took from eight to ten minims of the compound tincture of iodine for several weeks.

This patient was and is a total abstainer from all forms of alcohol.

Case XII. - Ascites from fibrous thickening of peritonaum. Eleven tappings, death and autopsy.

A man, aged 50, was admitted into hospital, July I I, I88I. He declared that he was not an habitual drinker of spirit or other alcoholics. Enlargement of the abdomen was first noticed in the Spring of I 878 . Jaundice existed at that time. The treatment and progress of the case were not noted in the history. He was in hospital in April, 1879 . The abdomen was then considerably enlarged; but the liquid diminished, and he was in a short time discharged. In August, I879, he was readmitted, and he was then tapped for the first time. He left the hospital, but was again admitted November 28 , and between this date and April I 2 th, he was tapped six times. He then returned to his duty as a watchman, and he did not again enter hospital until July i Ith, I88x. The ascites were now great, and he was tapped on July I $3^{\text {th }}$, I $88 \mathbf{r}$. The tapping was repeated October 6th, June $2 \mathrm{~d}, \mathbf{1} 882$, and in October, I882. Up to this time his general condition had been fair. In November, I 882 , it was noticed that he had pleurisy with effusion, and that the abdomen was much distended. The tapping was repeated November 2 Ist, the liquid withdrawn, being, for the first time, sero-purulent. Death, from exhaustion, occurred November 2 rst, 1882 .

The autopsy showed thickening, adherence and calcification of the pericardium. 'The heart was somewhat dilated, no valvular lesions. The legs were cedematous, and the right pleural cavity contained about two quarts of sero-fibrinous liquid. The left pleural surfaces were adherent, and the pleura greatly thickened.

The capsule of the liver was much thickened, and the organs slightly cirrhosed. The gastro-hepatic omentum was about an inch in thickness, and compressed the hepatic artery and the portal vein. The hepatic duct was situated above the thickened omentum. There was universal fibrous thickening of the peritonæum. Recent peritonitis was shown by the presence of exuded fibrin, and the peritoneal cavity contained sero-pus. The capsule of the spleen was much thickened. This organ was 6 inches in length, 4 inches wide, and 3 inches in thickness. The kidneys had undergone some fibrous degeneration.

\section{A COMPARISON OF ANTISEPTIC AND NON=ANTI- SEPTIC METHODS IN SURGERY.}

BY DR. DUIJEY P. ALLEN, I 77 EUCLID AVE., CIEVELANI), OHIO.

[Read to the Section on Surgery and Anatomy, Cleveland, June, 1883.] On May 20, when the committee were arranging the programme for this meeting, it was found that there was probably no paper that would directly in- 